\title{
Expression of glycolytic enzymes is increased in pancreatic cancerous tissues as evidenced by proteomic profiling by two-dimensional electrophoresis and liquid chromatography-mass spectrometry/mass spectrometry
}

\author{
KUNIKO MIKURIYA ${ }^{1,2}$, YASUHIRO KURAMITSU ${ }^{2}$, SHOMEI RYOZAWA ${ }^{1}$, MASANORI FUJIMOTO ${ }^{2}$, \\ SAYAKA MORI ${ }^{1,2}$, MASAAKI OKA ${ }^{3}$, KIMIKAZU HAMANO ${ }^{4}$, KIWAMU OKITA ${ }^{1}$, \\ ISAO SAKAIDA $^{1}$ and KAZUYUKI NAKAMURA ${ }^{2}$
}

\begin{abstract}
Departments of ${ }^{1}$ Gastroenterology and Hepatology, ${ }^{2}$ Biochemistry and Functional Proteomics, ${ }^{3}$ Digestive Surgery and Surgical Oncology and ${ }^{4}$ Surgery and Clinical Science, Yamaguchi University Graduate School of Medicine, Ube, Yamaguchi, Japan
\end{abstract}

Received November 14, 2006; Accepted January 16, 2007

\begin{abstract}
The prognosis of patients with pancreatic cancer is very poor because of late diagnosis and the lack of response to various therapies. We tried to identify proteins that might be available for early diagnosis and effective therapies by proteomic profiling of pancreatic cancer tissues. Pancreatic cancerous and paired non-cancerous tissues obtained from surgical resections or autopsies of 10 patients were analyzed by two-dimensional gel electrophoresis. The differential display showed 11 spots whose expression was increased in cancerous tissues compared with the paired non-cancerous tissues. The liquid chromatography-mass spectrometry/mass spectrometry (LC-MS/MS) system identified the spots as $\alpha$ enolase, glyceraldehyde-3-phosphate dehydrogenase (GAPDH), triosephosphate isomerase, transgelin, calmodulin, superoxide dismutase( $\mathrm{Mn})$ mitochondrial precursor, glutathione S-transferase $\mathrm{P}$, cyclophilin A, protein disulfide isomerase A3 precursor, and apolipoprotein A-I precursor. Two of the 11 spots were detected as GAPDH. We noticed that 4 of 11 spots were enzymes involved in glycolytic
\end{abstract}

Correspondence to: Professor Kazuyuki Nakamura, Department of Biochemistry and Functional Proteomics, Yamaguchi University Graduate School of Medicine, 1-1-1 Minami-Kogushi, Ube, Yamaguchi 755-8505, Japan

E-mail: nakamura@yamaguchi-u.ac.jp

Abbreviations: GAPDH, glyceraldehyde 3-phosphate dehydrogenase; TPI, triosephosphate isomerase; 2-DE, two-dimensional gel electrophoresis; MnSOD, superoxide dismutase(Mn) mitochondrial precursor; PDI-A3, protein disulfide isomerase A3 precursor; GST-p, glutathione S-transferase P

Key words: pancreatic adenocarcinoma, two-dimensional gel electrophoresis, $\alpha$-enolase, glyceraldehyde 3-phosphatase dehydrogenase, triosphosphate isomerase, transgelin pathway. Increased glycolysis in cancer cells has been regarded as the effect of intratumoral hypoxia and is possibly associated with tumor invasion, metastasis or resistance to therapies. These glycolytic proteins and transgelin, were confirmed by Western blotting and immunohistochemistry.

\section{Introduction}

Molecular diagnostics and thrapeutics for human malignancies have been developed recently. However, the prognosis of patients with pancreatic cancer is still very poor because of its aggressiveness and lack of early diagnosis and effective therapies (1). Surgical resection is the only curative therapy, but the disease has usually already progressed by the time of diagnosis. Therefore, novel diagnostic tools for pancreatic cancer have to be developed and the biological characteristics giving rise to aggressiveness of this disease should be clarified.

Recent intensive studies have identified genetic abnormalities frequently expressed in human malignancies, including pancreatic cancer (2-4). Following gene analysis, proteomic studies have been performed to find proteins as candidates for new diagnostic markers and therapeutic targets $(5,6)$.

Two-dimensional gel electrophoresis (2-DE) is regarded as a useful method to analyze proteins comprehensively. Using this method, we tried to identify proteins overexpressed in pancreatic cancerous tissues and to detect protein factors that might be available for diagnosis and more effective therapies.

\section{Materials and methods}

Tissue samples. We examined 10 pairs of cancerous and corresponding non-cancerous pancreas tissues obtained from patients who were diagnosed with pancreatic adenocarcinoma and underwent surgical resection or autopsy at Yamaguchi University Hospital between 2001 and 2004. The authors received informed consent for all patients, including 7 males and 3 females whose mean age at collection was 65 years (range, 51-79 years). None of the patients had received chemotherapy or radiation therapy prior to cancer resection. 
Histologically, 7 were classified as moderately differentiated tubular adenocarcinoma, 1 as well differentiated, 1 as poorly differentiated, and 1 as mucinous carcinoma. According to the TMN classification (7), 1 was classified as stage II, 6 as III, 1 as IVA, and 2 as IVB (Table I).

Sample preparation. Resected pancreas tissues were immediately frozen in liquid nitrogen and stored at $-80^{\circ} \mathrm{C}$ until use. They were disrupted and homogenized in lysis buffer $(1 \%$ NP-40, $1 \mathrm{mM}$ sodium vanadate, $1 \mathrm{mM}$ PMSF, $50 \mathrm{mM}$ Tris$\mathrm{HCl}, 10 \mathrm{mM}$ NaF, $10 \mathrm{mM}$ EDTA, $165 \mathrm{mM} \mathrm{NaCl}, 10 \mu \mathrm{g} / \mathrm{ml}$ leupeptin, $10 \mu \mathrm{g} / \mathrm{ml}$ aprotinin) using a microtube mixer with a teflon tip at $4{ }^{\circ} \mathrm{C}$ for $2 \mathrm{~h}$. The lysate was separated by centrifugation at $15,000 \mathrm{x} \mathrm{g}$ for $30 \mathrm{~min}$. The supernatant was stored at $-80^{\circ} \mathrm{C}$ until use.

Two-dimensional gel electrophoresis (2-DE). Three hundred micrograms of protein from the supernatant was applied to immobiline dry strips ( $\mathrm{pH} 3.0-10.0,7 \mathrm{~cm}$; Amersham Bioscience, $\mathrm{NJ}$ ) in a total volume of $125 \mu 1$ containing $8 \mathrm{M}$ urea, $2 \%$ CHAPS, $0.5 \%$ IPG buffer (Amersham Bioscience) and $2.8 \mathrm{mg} / \mathrm{ml}$ dithiothreitol (DTT). After dehydration for $14 \mathrm{~h}$, proteins were separated by isoelectrofocusing (IEF) at $20^{\circ} \mathrm{C}$ using $50 \mu \mathrm{A} /$ strips with the following linear voltage increases: $500 \mathrm{~V}$ for $1 \mathrm{~h}, 1000 \mathrm{~V}$ for $1 \mathrm{~h}$, and $8000 \mathrm{~V}$ for $2 \mathrm{~h}$. The strips were then equilibrated twice in $50 \mathrm{mM}$ Tris- $\mathrm{HCl}$ containing $6 \mathrm{M}$ urea, $30 \%$ glycerol and $2 \%$ sodium dodecyl sulfate (SDS) for $15 \mathrm{~min}$. DTT was then added, followed by iodoacetamide. The second dimension was performed on SDS-polyacrylamide gels (2-D homogeneous 12.5\%; Amersham Bioscience) in two steps: $600 \mathrm{~V}, 20 \mathrm{~mA}$ for $30 \mathrm{~min}$ and $600 \mathrm{~V}, 50 \mathrm{~mA}$ for $70 \mathrm{~min}$ in a multiphor horizontal electrophoresis unit (Amersham Pharmacia Biotechnology). Separated protein spots were stained on the gel with $30 \%$ methanol, $10 \%$ acetic acid, and $0.1 \%$ Coomassie Brilliant Blue R-250 (CBB) overnight. The gel was destained with $30 \%$ methanol and $10 \%$ acetic acid for $30 \mathrm{~min}$, and then with $7 \%$ acetic acid until the background of the spots turned clear.

Image analysis. The protein spots on the gel were recorded using an Agfa ARCUS 1200 ${ }^{\mathrm{TM}}$ image scanner (Agfa-Gevaert N.V., Mortsel, Belgium) and analyzed using Image Master 2D Platinum ver. 5.0 (Amersham Bioscience). Spots stained at different intensities between cancerous and non-cancerous tissues were excised from the gels and identified by LCMS/MS (LC-MSD XCT, Agilent).

In-gel digestion. The $\mathrm{CBB}$ dye was removed by rising the gel twice in $60 \%$ methanol containing $50 \mathrm{mM}$ ammonium bicarbonate and $5 \mathrm{mM}$ DTT for $15 \mathrm{~min}$ each time, and twice in $50 \%$ acetonitrile containing $50 \mathrm{mM}$ ammonium bicarbonate and $5 \mathrm{mM}$ DTT for $7 \mathrm{~min}$ each time. The gel piece was dehydrated in $100 \%$ acetonitrile, and then rehydrated with an in-gel digestion reagent containing $10 \mu \mathrm{g} / \mathrm{ml}$ sequencing grade trypsin (Promega, Madison, WI) in $30 \%$ acetonitrile with $50 \mathrm{mM}$ ammonium bicarbonate and $5 \mathrm{mM}$ DTT. The in-gel digestion was performed overnight at $30^{\circ} \mathrm{C}$.

Amino acid sequencing by LC-MS/MS. Lyophilized samples were dissolved in $20 \mu \mathrm{l}$ of $0.1 \%$ formic acid and centrifuged
Table I. Summary of all cases of pancreatic cancer.

\begin{tabular}{rcclcccc}
\hline No. & Age & Sex & Histology & T & N & M & Stage \\
\hline 1 & 71 & F & Tubular (moderate) & 3 & 0 & 0 & II \\
2 & 75 & M & Tubular (moderate) & 4 & 1 & 0 & IVA \\
3 & 54 & M & Tubular (moderate) & 2 & 1 & 0 & III \\
4 & 67 & F & Tubular (moderate) & 2 & 1 & 0 & III \\
5 & 79 & M & Mucinous & 4 & 1 & 1 & IVB \\
6 & 51 & F & Tubular (well) & 3 & 1 & 0 & III \\
7 & 61 & M & Tubular (poor) & 4 & 1 & 1 & IVB \\
8 & 64 & M & Tubular (moderate) & 3 & 1 & 0 & III \\
9 & 70 & M & Tubular (moderate) & 2 & 1 & 0 & III \\
10 & 58 & M & Tubular (moderate) & 3 & 1 & 0 & III \\
\hline
\end{tabular}

M, male; F, female; tubular, tubular adenocarcinoma; well, well differentiated; moderate, moderately differentiated; poor, poorly differentiated type; mucinous, mucinous carcinoma. Tumor staging was performed according to the TMN classification.

at $15,000 \mathrm{x}$ g for $5 \mathrm{~min}$. Peptide sequencing of identified protein spots was performed using the LC-MS/MS system with a Spectrum Mill MS Proteoics Workbench (Agilent Technologies, Santa Clara, CA).

Statistical analysis. Expression levels of the protein spots were quantified by analyzing the intensity of each spot with Image Master (Amersham Bioscience). The differences in expression between cancerous tissues and non-cancerous tissues were analyzed by Student's t-test.

Western blot analysis. Protein samples of $15 \mu \mathrm{g}$ were separated by SDS-PAGE and $100 \mu \mathrm{g}$ were separated by 2-DE. Fractionated proteins were transferred electrophoretically onto a PVDF membrane and blocked with TBS containing 5\% skim milk. Primary antibodies used were anti-enolase goat polyclonal antibody (1:200), anti-GAPDH polyclonal antibody (1:200), anti-triosephosphate isomerase polyclonal antibody (1:200) and anti-transgelin goat polyclonal antibody (1:250) (from Santa Cruz Biotechnology, Inc., Santa Cruz, CA). Membranes were incubated for $1 \mathrm{~h}$, washed four times with TBS containing $0.05 \%$ Tween-20, incubated for $1 \mathrm{~h}$ with a secondary antibody $(1: 2,000)$, and developed with a chemiluminescence reagent (ECL; Amersham Bioscience).

Immunohistochemical analysis. Immunohistochemical analysis was performed using ABC Kit (Vector Laboratories, Burlingame, CA) on the same samples as tissue specimens described in Tissue samples. The primary antibodies were the same as those used for Western blot analysis and used at dilutions of $1: 200$ or $1: 250$.

\section{Results}

Detection of protein spots on 2-DE gels. At least 190 protein spots were matched on each 2-DE gel. The differential 


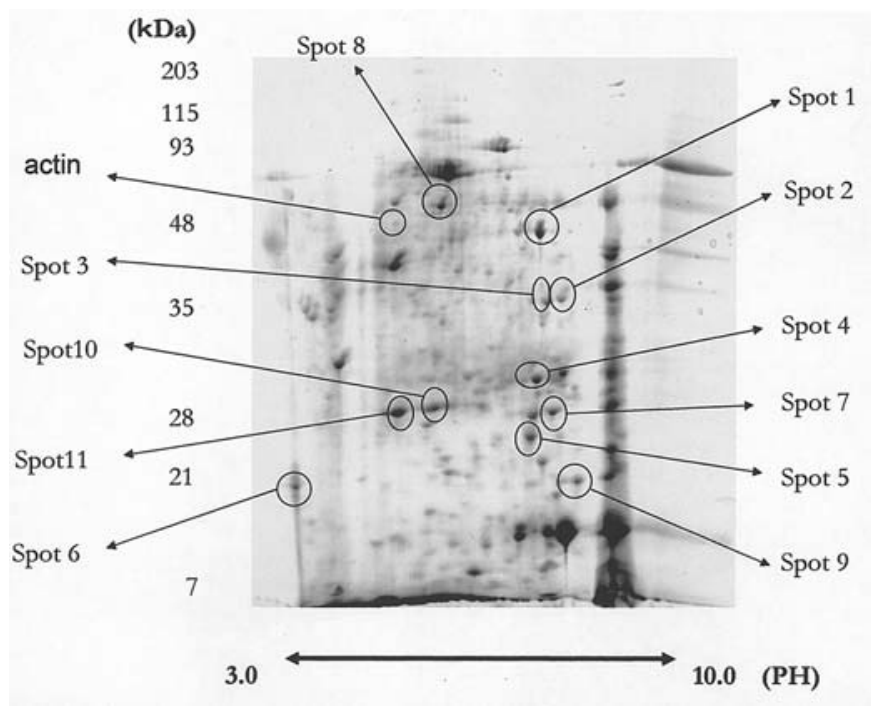

Figure 1. Protein patterns obtained by 2-DE of cancerous tissues and paired non-cancerous tissues of patients with pancreatic adenocarcinoma. Proteins were separated on $\mathrm{pH}$ 3-10 linear, immobilized $\mathrm{pH}$ gradient strips and then by $12.5 \%$ SDS-PAGE. Gels were stained with CBB R-250. Eleven spots were up-regulated in cancerous tissues and numbered from 1 to 11 .

expression of paired cancerous and non-cancerous tissues was visually compared. Eleven spots were up-regulated in cancerous tissues in at least 4 of the 10 samples by $\geq 2$-fold higher intensity (Figs. 1 and 2).

Identification of proteins. The LC-MS/MS system identified these up-regulated protein spots as $\alpha$-enolase (spot 1), glycer- aldehyde-3-phosphate dehydrogenase (GAPDH) (spots 2 and 3), triosephosphate isomerase (spot 4), transgelin (spot 5), calmodulin (spot 6), MnSOD (spot 7), PDI-A3 (spot 8), cyclophilin A (spot 9), GST-P (spot 10), and apolipoprotein A-I precursor (spot 11). In Table II, information about the eleven spots is summarized.

Expression profiles of proteins. In all 10 paired samples, the intensities of the 11 protein spots were analyzed and quantified using Image Master (Table III). The expression of four proteins, $\alpha$-enolase, GAPDH, triosephosphate isomerase and transgelin were confirmed by 2-D immunoblot analysis (Fig. 3). The intensity of each spot was increased in cancerous tissues. In 2-D immunoblot analysis, $\alpha$-enolase, GAPDH and TPI were observed as multiple spots with slightly different isoelectric points or molecular weights. These spots may be explained by post translational modifications of the proteins. We can also detect some of these spots on 2-DE gels stained by $\mathrm{CBB}$.

The expression of $\alpha$-enolase, GAPDH, TPI and transgelin was also confirmed by immunohistochemistry. $\alpha$-enolase and GAPDH were predominantly expressed in cancer cells. $\alpha$-enolase was also detected in islet cells. While weak staining was detected in normal epithelial cells, acinar cells and in stromal cells. TPI was detected predominantly in cancer cells and also detected in normal epithelial cells. TPI was barely detectable in acinar cells, stromal cells and islet cells. Transgelin was mainly expressed in stromal cells but not in cancer cells or normal epithelial cells. We found that transgelin expression was much stronger in stromal cells around cancer cells than in those around normal epithelial cells (Fig. 4).
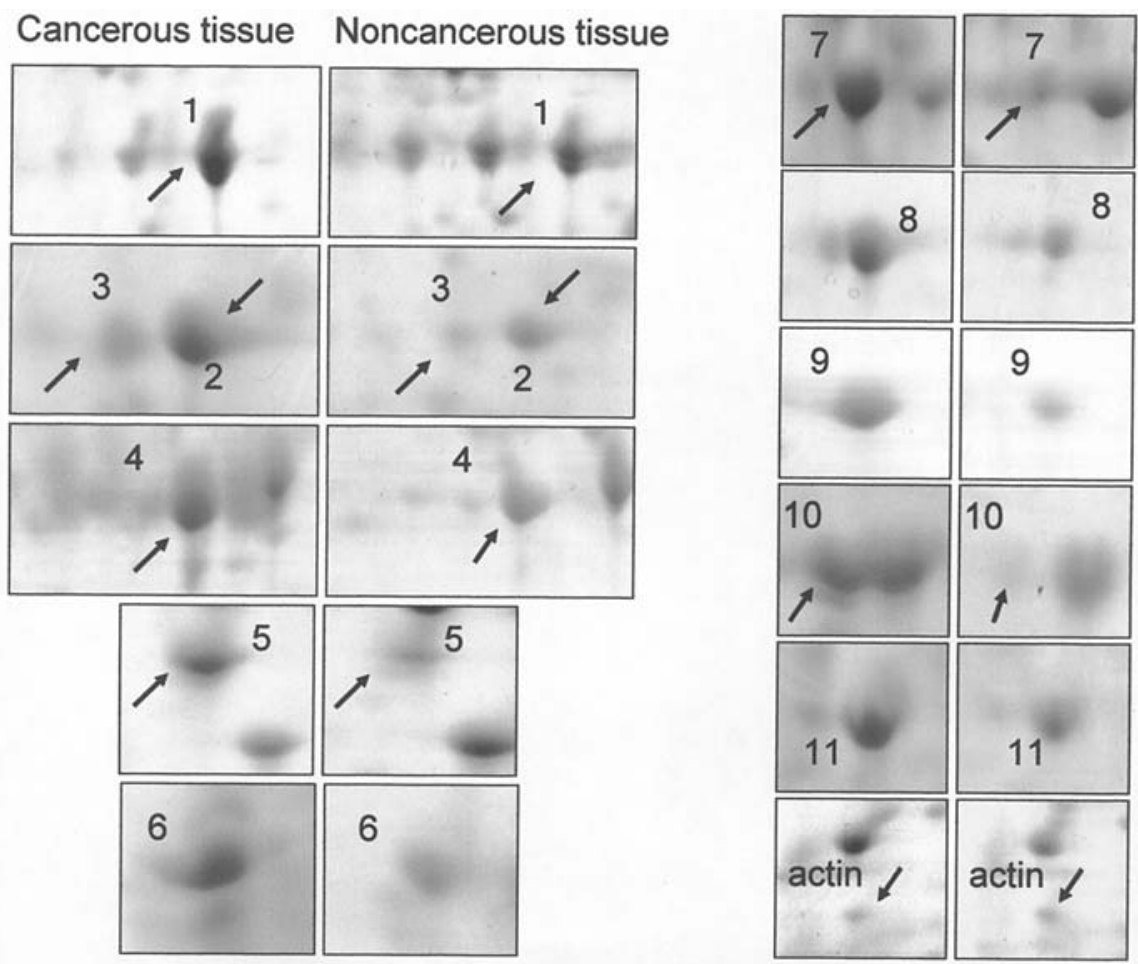

Figure 2. Comparison of 2-DE patterns between cancerous tissues and non-cancerous tissues. Eleven spots up-regulated in cancerous tissues are shown. $\alpha$-enolase (1), two spots of GAPDH (2, 3), triosephosphate isomerase (4), transgelin (5), calmodulin (6), MnSOD (7), protein disulfide isomerase A3 (8), cyclophilin A (9), GST-P (10), apolipoprotein A-I (11). Each spot number is the same as those in Fig. 1. 
Table II. Up-regulated proteins in pancreatic cancerous tissues.

\begin{tabular}{|c|c|c|c|c|}
\hline Spot & Frequency & Mass Mr/pl & Accession no. & Protein \\
\hline 1 & $9 / 10$ & $47037 / 6.99$ & P06733 & $\alpha$-enolase \\
\hline 2 & $8 / 10$ & $35922 / 8.58$ & P04406 & $\begin{array}{l}\text { Glyceraldehyde 3-phosphate } \\
\text { dehydrogenase, liver type }\end{array}$ \\
\hline 3 & $8 / 10$ & $35922 / 8.58$ & P04406 & $\begin{array}{l}\text { Glyceraldehyde 3-phosphate } \\
\text { dehydrogenase, liver type }\end{array}$ \\
\hline 4 & $7 / 10$ & $26538 / 6.51$ & P60175 & Triosephosphate isomerase \\
\hline 5 & $6 / 10$ & $22479 / 8.88$ & Q01955 & Transgelin \\
\hline 6 & $6 / 10$ & $16706 / 4.09$ & P02593 & Calmodulin \\
\hline 7 & $5 / 10$ & $24722 / 8.34$ & P04179 & $\begin{array}{l}\text { Superoxide dismutase }(\mathrm{Mn}) \text {, } \\
\text { mitochondrial precursor }\end{array}$ \\
\hline 8 & $6 / 10$ & $56782 / 5.99$ & P30101 & $\begin{array}{l}\text { Protein disulfide isomerase } \\
\text { A3 precursor }\end{array}$ \\
\hline 9 & $5 / 10$ & $17881 / 7.82$ & P05092 & $\begin{array}{l}\text { Peptydyl-prolyl cis-trans isomerase } \\
\text { (cyclophilin A) }\end{array}$ \\
\hline 10 & $4 / 10$ & $23224 / 5.44$ & P09211 & Glutatione S-transferase $\mathrm{P}$ \\
\hline 11 & $4 / 10$ & $30778 / 5.56$ & P02647 & Apolipoprotein A-I precursor \\
\hline
\end{tabular}

Table III. The intensities of the up-regulated protein spots in cancerous tissues.

\begin{tabular}{lcccr}
\hline & \multicolumn{2}{c}{ Spot intensity (average \pm SD) } & & \\
\cline { 2 - 4 } Protein & Cancerous tissue & Non-cancerous tissue & Ratio of spot intensity & p-value \\
\hline$\alpha$ enolase & $0.30 \pm 0.24$ & $0.12 \pm 0.11$ & 2.46 & 0.0058 \\
GAPDH & $0.19 \pm 0.15$ & $0.07 \pm 0.05$ & 2.95 & 0.0145 \\
GAPDH & $0.11 \pm 0.04$ & $0.04 \pm 0.04$ & 3.91 & 0.0131 \\
TPI & $0.38 \pm 0.27$ & $0.17 \pm 0.11$ & 2.2 & 0.0449 \\
Transgelin & $0.34 \pm 0.29$ & $0.13 \pm 0.10$ & 2.62 & 0.0434 \\
Calmodulin & $0.36 \pm 0.23$ & $0.14 \pm 0.14$ & 2.55 & 0.0059 \\
MnSOD & $0.34 \pm 0.03$ & $0.17 \pm 0.004$ & 6.36 & 0.0191 \\
PDI-A3 & $0.43 \pm 0.09$ & $0.09 \pm 0.004$ & 6.34 & 0.0203 \\
Cyclophilin A & $0.20 \pm 0.005$ & $0.11 \pm 0.003$ & 2.31 & 0.0161 \\
GST-P & $0.33 \pm 0.02$ & $0.15 \pm 0.003$ & 4.20 & 0.0370 \\
Apolipoprotein A-I & $0.55 \pm 0.07$ & $0.21 \pm 0.007$ & 2.66 & 0.0175 \\
\hline
\end{tabular}

\section{Discussion}

In this study, we detected 11 protein spots whose expression increased in human pancreatic adenocarcinoma tissues. Interestingly, four of them, $\alpha$-enolase, two spots of GAPDH, and triosephosphate isomerase, were enzymes involved in the glycolytic pathway. It is known that increased rates of glucose uptake and glycolysis are generally found in tumor cells (8). Hypoxia inducible factor (HIF-1), which is expressed under hypoxic conditions with tumor proliferation, has been shown to activate transcription of genes encoding vascular endothelial growth factor, glucose transporters, and glycolytic enzymes, including $\alpha$-enolase and GAPDH $(9,10)$. Upregulation of the three enzymes might be caused by hypoxia and increased activity of glycolysis.

$\alpha$-enolase has been reported to be up-regulated in several cancer cell lines in previous proteomic studies using 2-DE $(11,12) . \alpha$-enolase is found in the cytoplasm of most cells and works as a glycolytic enzyme. Previous studies have reported its ability to function as a heat shock protein (13), cell surface receptor for plasminogen (14), and as a Myc-binding protein that negatively regulates transcription of the c-myc oncogene 
Cancerous tissue (C) Noncancerous tissue (NC)

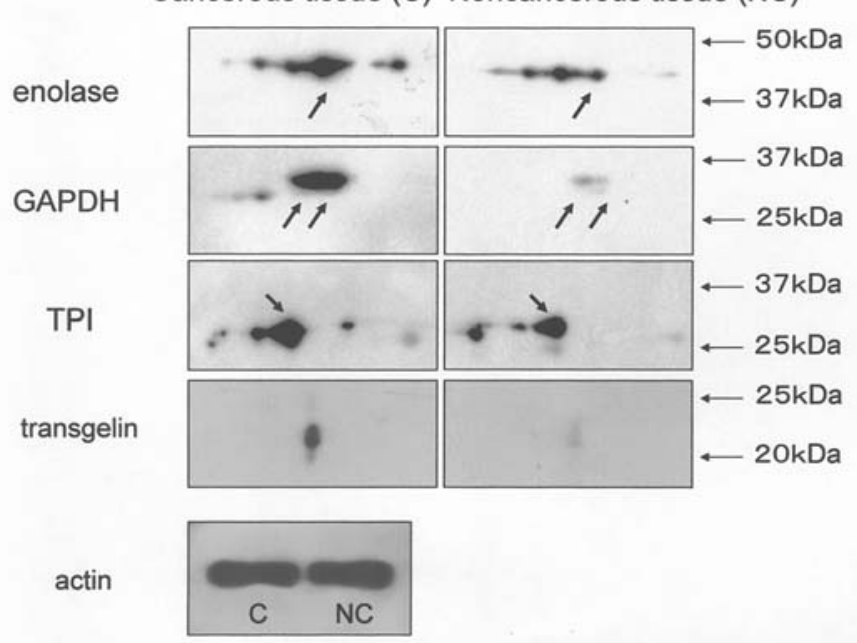

Figure 3. 2-D immunoblot analysis of up-regulated proteins in pancreatic cancerous tissues. We used three pairs of samples for each 2-D immunoblot analysis of $\alpha$-enolase, GAPDH, triosephosphate isomerase and transgelin. Protein expression of all 4 increased in cancerous tissues.

in the nucleus $(15,16)$. Enolase has three isoenzymes: $\alpha$-enolase is found in a variety of tissues including liver, $\beta$-enolase in muscle tissues and $\gamma$-enolase in neurons and neuroendocrine tissues (17). Enolase exists in heterodimetric forms such as $\alpha \alpha, \alpha \beta, \beta \beta, \alpha \beta$ and $\gamma \gamma$ (18). Neuron-specific enolase (NSE, $\alpha \gamma$ and $\gamma \gamma$ isoforms) in serum of small cell lung carcinoma and neuroblastoma is known to be a useful marker for monitoring the progression of disease and response to treatment $(19,20)$. Gerbitz et al showed that $\gamma$-enolase was increased in the plasma of patients suffering from small cell lung carcinoma, while most patients with squamous cell carcinoma of the lung or prostatic cancer exhibited normal $\gamma$-enolase and high concentrations of $\alpha$-enolase (21). Oskam et al studied expression of enolase isoenzymes in rat medullary thyroid carcinomas and reported that the $\alpha \gamma$ and $\gamma \gamma$ isoenzyme levels were relatively high in well-differentiated rat tumors, whereas the majority of enolase isoenzymes were $\alpha \alpha$ in undifferentiated and anaplastic tumors (22). Takashima et al reported a relation between the expression of $\alpha$-enolase and differentiation of hepatocellular carcinoma (23). In heart and skeletal muscles of the rat, the $\alpha \alpha$ isoenzyme predominates in the fetus; however, this isoenzyme is replaced by the $\alpha \beta$ and $\beta \beta$ types as development progresses (24-26). These results might suggest that the expressed form of enolase is associated not only with tissue specificity of the three isoenzymes, but also with the degree of cell differentiation. Further experiments will be required to determine whether $\alpha$-enolase increases in serum of patients with pancreatic adenocarcinoma and to clarify the relationship between the expression of enolase and cell differentiation.

GAPDH has been known as a housekeeping protein whose gene expression remains constant in spite of various cellular conditions. In recent years, however, that view has changed since GAPDH has proved to have diverse cellular functions, including nuclear RNA export, DNA replication, DNA repair, exocytotic membrane fusion, cytoskeletal organization, and phosphotransferase activity (27). Indeed, increased expression levels of GAPDH mRNA were reported in many malignant tumors (28-30), including pancreatic adenocarcinoma (31). Some of these reports showed that GAPDH expression levels were associated with hypoxic conditions $(32,33)$ and the

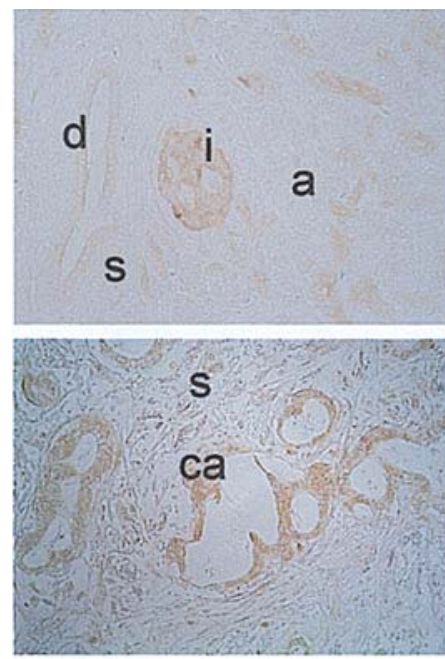

enolase $(1: 200)$
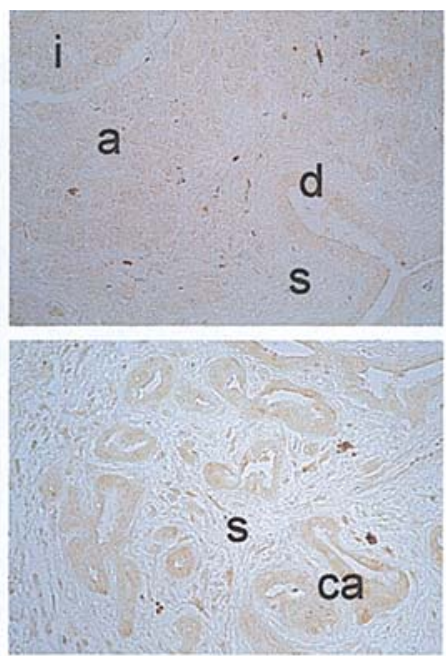

GAPDH $(1: 200)$
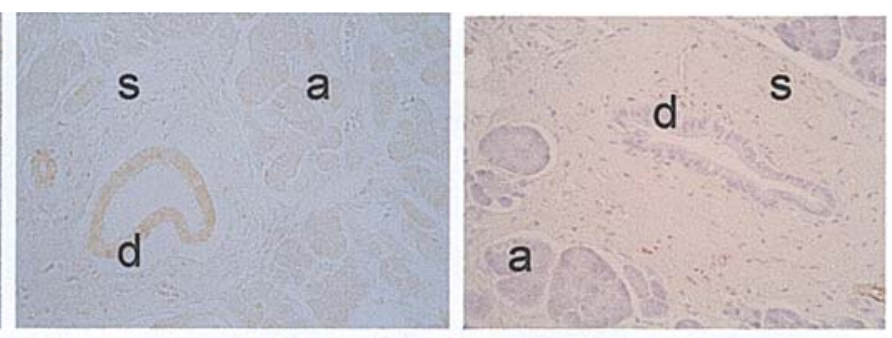

S

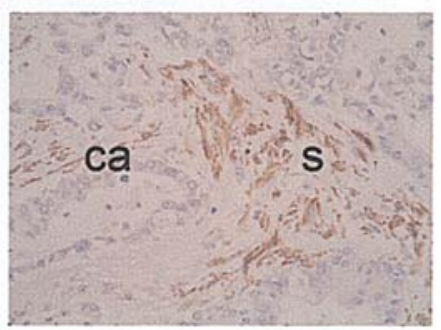

TPI (1:200)

Figure 4. Immunohistochemistry staining of $\alpha$-enolase, GAPDH, triosephosphate isomerase (TPI) and transgelin. $\alpha$-enolase and GADPH were predominantly expressed in tumor cells. $\alpha$-enolase was also detected in islet cells, while weak staining was found in acinar cells and in stromal cells. TPI was detected predominantly in cancer cells and also detected in normal epithelial cells. TPI was barely detectable in acinar cells, stromal cells and islet cells. Transgelin was mainly expressed in stromal cells and its expression was much stronger in stromal cells around cancer cells than in normal epithelial cells. We did not detect transgelin expression in cancer cells or in normal epithelial cells. d, non-cancerous pancreatic ductal cell; ca, cancerous pancreatic ductal cell; a, acinar cell; i, islet cell; s, stromal cell. 
aggressiveness of tumors $(34,35)$. Epner and Coffey have analyzed GAPDH expression in normal and malignant human prostate tissues and reported that GAPDH is abundant in the nucleus in normal prostate basal cells, but in cytoplasm of prostate cancer cells (36). They also found five forms of GAPDH with isoelectric points in metastatic rat prostate cancer cell lines, but one to four forms in non-metastatic cell lines, suggesting that each of them has a unique function. In our study, we detected two forms of GAPDH overexpressed in cancerous tissues. Further examination is necessary to analyze their functions and localization.

Triosephosphate isomerase (TPI) has been reported to be up-regulated in lung adenocarcinoma (37), melanoma (38), and squamous metaplasia and carcinoma of the bladder (39). The mRNA and protein expression of TPI has also been shown to be increased by hypoxia (40), but the mechanism is unknown. Recent studies identified a mutated form of TPI known as HLA-DR4-restricted melanoma antigen, which may become a target for immunotherapies for cancer $(41,42)$.

Transgelin, which is also identical to SM22- $\alpha$, is reported as predominantly expressed in smooth muscle cells and fibroblasts. It was shown to play a role in cell transformation and shape change by binding actin and gelling it $(43,44)$. Tansgelin expression is observed to be lost in human breast and colon tumor samples. Down-regulation of it may associate with oncogenic Ras (45). In renal cell carcinoma (RCC), in situ hybridization revealed that transgelin is not expressed in the malignant cells but in mesenchymal cells of the tumor stroma (46). This report corresponds to the result of immunohistochemistry of transgelin in this study. Gene expression of transgelin is found to be up-regulated in the cell lines from metastatic lesions of RCC (47). Recent study identified the expression of this protein as down-regulated in microdissected cells of Pan IN-2 grades, precursor lesions of pancreatic ductal adenocarcinoma (48).

Ott et al and Kellner et al reported proteomic study using epithelial cell preparation procedure by epithelial cell surface antibody Ber-Ep4 $(49,50)$. Shekouh et al showed that the protein profiles of undissected normal or malignant pancreas differed from those of normal or malignant pancreatic ductal epithelia dissected by laser capture microdissection (51). But they also noted that the undissected and dissected tumor samples showed similar profiles. Our data indicate that particularly non-malignant samples may include many proteins that are expressed in cells other than ductal cells. In this study, we reported only on increased proteins in cancerous tissues because many of the decreased proteins may have originated from non-epithelial cells.

It is important to clarify proteins expressed specific to cancer cells although we consider the protein profile from whole tissue biopsies to have important information because recent studies have noted that invasion and tumor metastasis are closely related to interaction between cancer cells and the surrounding tissues (52). Especially, pancreatic cancer is characterized by abundant stroma cells, so the study using whole tissues including stroma cells may help to identify proteins participating in invasion and metastasis of pancreatic cancer.

Almost all of these identified proteins are expressed not only in cancerous tissues but also in non-cancerous tissues and most of them were previously reported as differentially expressed in types of human cancer other than pancreatic. So the possibility that these proteins are specific markers of pancreatic cancer is humble, but they may reflect the mechanism of the cancer spreading.

The number of patients included in this study is not sufficient to produce any conclusion. The sample size would need to be larger in heterogeneous tissue samples from a multi-gender, and multi-age cohort of humans (53). Studies should be continued to confirm these results.

In this study, 10 proteins overexpressed in pancreatic adenocarcinoma were detected. In order to clarify the role of these proteins in pathogenesis and to estimate whether these proteins are useful for developing new diagnostic markers or therapies, further study is needed. Although it is difficult to obtain samples of early pancreatic cancer, it is particularly important to clarify if these proteins are expressed in the early stage of pancreatic cancer.

\section{Acknowledgements}

This study was supported in part by Grants-in-Aid from the Ministry of Education, Culture, Sports, Science, and Technology of Japan (No. 17659166 to Y. Kuramitsu and No. 16659742 to K. Nakamura).

\section{References}

1. Murr MM, Sarr MG, Oishi AJ and van Heerden JA: Pancreatic cancer. CA Cancer J Clin 44: 304-318, 1994.

2. Harada T, Okita K, Shiraishi K, et al: Detection of genetic alterations in pancreatic cancers by comparative genomic hybridization coupled with tissue microdissection and degenerate oligonucleotide primed polymerase chain reaction. Oncology 62: 251-258, 2002.

3. Yatsuoka T, Sunamura M, Furukawa T, et al: Association of poor prognosis with loss of 12q, 17p, and 18q, and concordant loss of $6 \mathrm{q} / 17 \mathrm{p}$ and $12 \mathrm{q} / 18 \mathrm{q}$ in human pancreatic ductal adenocarcinoma. Am J Gastroenterol 95: 2080-2085, 2000.

4. Sakai Y, Yanagisawa A, Shimada M, et al: K-ras gene mutations and loss of heterozygosity at the p53 gene locus relative to histological characteristics of mucin-producing tumors of the pancreas. Hum Pathol 31: 795-803, 2000.

5. Takashima M, Kuramitsu Y, Yokoyama Y, et al: Proteomic profiling of heat shock protein 70 family members as biomarkers for hepatitis $C$ virus-related hepatocellular carcinoma. Proteomics 3: 2487-2493, 2003.

6. Yokoyama Y, Kuramitsu Y, Takashima M, et al: Proteomic profiling of proteins decreased in hepatocellular carcinoma from patients infected with hepatitis C virus. Proteomics 4: 2111-2116, 2004.

7. UICC: TNM Classification of Malignant Tumors. 6th edition. Wiley-Liss, 2002.

8. Boros LG, Lee WN and Go VL: A metabolic hypothesis of cell growth and death in pancreatic cancer. Pancreas 24: 26-33, 2002.

9. Graven KK, Yu Q, Pan D, Roncarati JS and Farber HW: Identification of an oxygen responsive enhancer element in the glyceraldehyde-3-phosphate gene. Biochem Biophys Acta 1447: 208-218, 1999.

10. Semenza GL, Jiang BH, Lueng SW, et al: Hypoxia response elements in the aldolase A, enolase 1, and lactate dehydrogenase A gene promoters contain essential binding sites for hypoxiainducible factor 1. J Biol Chem 271: 32529-32537, 1996.

11. Srisomsap C, Sawangareetrakul P, Subhasitonont P, et al: Proteomic analysis of cholangiocarcinoma cell line. Proteomics 4: 1135-1144, 2004.

12. Stierum R, Gaspari M, Dommels Y, et al: Proteome analysis reveals novel proteins associated with proliferation and differentiation of the colorectal cancer cell line Caco-2. Biochem Biophys Acta 1650: 73-91, 2003. 
13. Idea $\mathrm{H}$ and Yahara I: Yeast heat-shock protein of $\mathrm{Mr} 48,000$ is an isoprotein of enolase. Nature 315: 688-690, 1985.

14. Pancholi V: Multifunctional alpha-enolase: its role in diseases. Cell Mol Life Sci 58: 902-920, 2001.

15. Subramanian A and Miller DM: Structural analysis of alphaenolase. Mapping the functional domains involved in downregulation of the c-myc protooncogene. J Biol Chem 275: 5958-5965, 2000.

16. Feo S, Arcuri D, Piddini E, Passantino R and Giallongo A: ENO1 gene product binds to the c-myc promoter and acts as a transcriptional repressor: relationship with Myc promoterbinding protein 1 (MBP-1). FEBS Lett 473: 47-52, 2000.

17. Marangos PJ, Zis AP, Clark RL and Goodwin FK: Neuronal, non-neuronal and hybrid forms of enolase in brain: structural, immunological and functional comparisons. Brain Res 150: 117-133, 1978.

18. Kato K, Asai R, Shimizu A, Suzuki F and Ariyoshi Y: Immunoassay of three enolase isozymes in human serum and in blood cells. Clin Chim Acta 127: 353-363, 1983.

19. Gendreau V, Montravers F, Philippe C and Talbot JN: Reevaluation of the usefulness of systematic bone scanning in initial staging and follow-up of small cell lung carcinoma, taking into account the serum levels of neuron-specific enolase. Int J Biol Markers 12: 148-153, 1997.

20. Eriksson B, Oberg K and Stridsberg M: Tumor markers in neuroendocrine tumors. Digestion 62: S33-S38, 2000.

21. Gerbitz KD, Summer J, Schumacher T, Amold H, Kraft A and Mross K: Enolase isoenzymes as tumour markers. J Clin Chem Clin Biochem 24: 1009-1016, 1986.

22. Oskam R, Rijksen G, Lips CJ and Staal GE: Enolase isozymes in differentiated and undifferentiated medullary thyroid carcinomas. Cancer 55: 394-399, 1985.

23. Takashima M, Kuramitsu Y, Fujimoto M, et al: Overexpression of alpha enolase in hepatitis $\mathrm{C}$ virus-related hepatocellular carcinoma: association with tumor progression as determined by proteomic analysis. Proteomics 5: 1686-1692, 2005.

24. Reider CC and Taylor CB: Enolase isoenzymes. II. Hybridization studies, developmental and phylogenic aspects. Biochem Biophys Acta 405: 175-187, 1975.

25. Merkulova T, Lucas M, Jabet C, et al: Biochemical characterization of the mouse muscle-specific enolase: developmental changes in electrophoretic variants and selective binding to other proteins. Biochem J 323: 791-800, 1997.

26. Reider CC and Taylor CB: Enolase isoenzymes in rat tissues. Electrophoretic, chromatographic, immunological and kinetic properties. Biochem Biophys Acta 365: 288-303, 1974.

27. Sirover MA: New insights into an old protein: the functional diversity of mammalian glyceraldehyde-3-phosphate dehydrogenase. Biochim Biophys Acta 1432: 159-184, 1999.

28. Tokunaga K, Nakamura Y, Sakata K, Fujimori K, Ohkubo M, Sawada K and Sakiyama S: Enhanced expression of a glyceraldehyde-3-phosphate dehydrogenase gene in human lung cancers. Cancer Res 47: 5616-5619, 1987.

29. Epner DE, Partin AW, Schalken JA, Issacs JT and Coffey DS: Association of glyceraldehyde-3-phosphate dehydrogenase expression with cell motility and metastatic potential of rat prostatic adenocarcinoma. Cancer Res 53: 1995-1997, 1993.

30. Vila MR, Nicolas A, Morote J, De I and Meseguer A: Increased glyceraldehyde-3-phosphate dehydrogenase expression in renal cell carcinoma identified by RNA-based, arbitrarily primed polymerase chain reaction. Cancer 89: 152-164, 2000.

31. Schek N, Hall BL and Finn OJ: Increased glyceraldehyde-3phosphate dehydrogenase gene expression in human pancreatic adenocarcinoma. Cancer Res 48: 6354-6359, 1988.

32. Zhong H and Simons JW: Direct comparison of GAPDH, betaactin, cyclophilin, and 28S rRNA as internal standards for quantifying RNA levels under hypoxia. Biochem Biophys Res Commun 259: 523-526, 1999.

33. Salnikow K, Costa M, Figg WD and Blagosklonny MV: Hyperinducibility of hypoxia-responsive genes without p53/p21dependent checkpoint in aggressive prostate cancer. Cancer Res 60: 5630-5634, 2000.
34. Revillion F, Pawlowski V, Hornez L and Peyrat JP: Glyceraldehyde-3-phosphate dehydrogenase gene expression in human breast cancer. Eur J Cancer 36: 1038-1042, 2000.

35. Tarbe N, Evtimova V, Burtscher H, Jarsch M, Alves F and Weidle UH: Transcriptional profiling of cell lines derived from an orthotopic pancreatic tumor model reveals metastasis-associated genes. Anticancer Res 21: 3221-3228, 2001

36. Epner DE and Coffey DS: There are multiple forms of glyceraldehyde-3-phosphate dehydrogenase in prostate cancer cells and normal prostate tissue. Prostate 28: 372-378, 1996.

37. Chen G, Gharib TG, Huang CC, et al: Proteomic analysis of lung adenocarcinoma: identification of a highly expressed set of proteins in tumors. Clin Cancer Res 8: 2298-2305, 2002.

38. Clauser KR, Hall SC, Smith DM, et al: Rapid mass spectrometric peptide sequencing and mass matching for characterization of human melanoma proteins isolated by two-dimensional PAGE. Proc Natl Acad Sci USA 92: 5072-5076, 1995.

39. Montgomerie JZ, Gracy RW, Holshuh HJ, Keyser AJ, Bennett CJ and Schick DG: The $28 \mathrm{~K}$ protein in urinary bladder, squamous metaplasia and urine is triosephosphate isomerase. Clin Biochem 30: 613-618, 1997.

40. Gress B, Hobauer KH, Deutzmann R and Kurtz A: Hypoxia upregulates triosephosphate isomerase expression via a HIFdependent pathway. Pflugers Arch 448: 175-180, 2004.

41. Wang RF, Wang W, Atwood AC, Topalian SL and Rosenberg SA: Cloning genes encoding MHC class II-restricted antigens: mutated CDC27 as a tumor antigen. Science 284: 1351-1354, 1999.

42. Pieper R, Christian RE and Gonzales MI: Biochemical identification of a mutated human melanoma antigen recognized by CD4(+) T cells. J Exp Med 189: 757-766, 1999.

43. Shapland C, Hsuan JJ, Totty NF and Lawson D: Purification and properties of transgelin: a transformation and shape change sensitive actin-gelling protein. J Cell Biol 121: 1065-1073, 1993.

44. Lawson D, Harrison M and Shapeland C: Fibroblast transgelin and smooth muscle SM22alpha are the same protein, the expression of which is down-regulated in many cell lines. Cell Motil Cytoskeleton 38: 250-257, 1997.

45. Shields JM, Rogers-Graham K and Der CJ: Loss of transgelin in breast and colon tumors and in RIE-1 cells by Ras deregulation of gene expression through Raf-independent pathways. J Cell Biol 277: 9790-9799, 2002.

46. Klade CS, Voss T, Krystek E, Ahorn H, Zatloukal K, Pummer K and Adolf GR: Identification of tumor antigens in renal cell carcinoma by serological proteome analysis. Proteomics 1: 890-898, 2001.

47. Ami Y, Shimazui T, Akaza H, Uematsu N, Yano Y, Tsujimoto G and Uchida K: Gene expression profiles correlate with the morphology and metastasis characteristics of renal cell carcinoma cells. Oncol Rep 13: 75-80, 2005.

48. Sitek B, Luttges J, Marcus K, et al: Application of fluorescence difference gel electrophoresis saturation labelling for the analysis of microdissected precursor lesions of pancreatic ductal adenocarcinoma. Proteomics 5: 2665-2679, 2005.

49. Ott V, Guenther K, Steinert R, Tortola S, Borisch B, Schlegel W and Reymond MA: Accuracy of two-dimensional electrophoresis for target discovery in human colorectal cancer. Pharmacogenomics J 1: 142-151, 2001.

50. Kellner U, Steinert R, Seibert V, et al: Epithelial cell preparation for proteomic and transcriptomic analysis in human pancreatic tissue. Pathol Res Pract 200: 155-163, 2004.

51. Shekouh AR, Thompson CC, Prime W, et al: Application of laser capture microdissection combined with two-dimensional electrophoresis for the discovery of differentially regulated proteins in pancreatic ductal adenocarcinoma. Proteomics 3: 1988-2001, 2003.

52. Keleg S, Buchler P, Ludwig R, Buchler MW and Friess H: Invasion and metastasis in pancreatic cancer. Mol Cancer 2: 1-14, 2003.

53. Hu L, Evers S, Lu ZH, Shen Y and Chen J: Two-dimensional protein database of human pancreas. Electrophoresis 25: 512-518, 2004. 